\title{
Yatırımcılarda Risk Toleransı ve Aşırı Güven Arasındaki İlişki ${ }^{1}$
}

DOI: 10.26466/opus.928314

\author{
$*$ \\ Yasemin Kuyucular* - Durmus Sezer** \\ *Dr, Adnan Menderes Üniversitesi, SBE Enstitüsü, Aydın/Türkiye \\ E-Posta: yaseminkuyucular@gmail.com \\ ORCID: $\quad$ 0000-0001-8131-0809 \\ **Dr. Öğr. Üyesi, ADÜ Aydın İktisat Fakültesi, İşletme Bölümü, Aydın/Türkiye \\ E-Posta: durmus.sezer@adu.edu.tr \\ ORCID: $\quad$ 0000-0003-4992-8312
}

Öz

Finansal piyasalarda yatırım kararların birçok faktörün etkilediği ve karar almayı zorlaştırdı̆̆g yadsınamaz bir gerçektir. Karar almayı zorlaştıran sebepler; yatırımonın kendisinden kaynaklı ve kendisi dışındaki sebepler olmak üzere temelde ikiye ayrılabilir. Bireysel yatırımciların kişisel özellikleri ve davranışları yatırım kararın etkileyen en önemli unsurlardandır. Bu çalışmanın amaci; bireysel yatırımciların risk tolerans düzeylerini saptamak ve risk tolerans düzeylerine etki eden aşır güven kavramı ile aralarındaki ilişkiyi incelemektir. Bu bağlamda, çalışmada Türkiye'deki bireysel yatırımcıların risk toleransları ve aşırı güven davranışları detaylı olarak araştırılmıştır. Çalışma kapsaminda; İstanbul, Ankara ve İzmir illerinde ikamet eden 520 bireysel yatırmoiya anket uygulanmıştır. Analiz sonucuna göre yatırımciların aşırı güvenleri ile risk toleransları arasında anlamlı bir ilişki bulunmuştur. Buna göre, aşırı güven düzeyi yükseldikçe risk tolerans düzeyi de yükselmektedir. Çalışmanın devamında risk toleransı, bileşenlerine ayrılmıştır. Bulgulara göre, yatırımcıların aşırı güvenleri ile yatırım riskleri ve finansal riskleri arasında anlamlı bir ilişkiye rastlanırken, spekülatif risk ile aşırı güven arasında anlamlı bir ilişkiye rastlanmamıştır.

Anahtar Kelimeler: Davranışsal Finans, Finansal Karar Alma, Yatırımcı Psikolojisi, Risk Toleransı, Aşırı Güven.

\footnotetext{
${ }^{1}$ Bu çalışma "Bireysel Yatııımcılarda Risk Toleransı ve Aşırı Güven Kavramının Karşılaştırmalı Olarak incelenmesi" adlı doktora tezinden türetilmiştir.
} 


\title{
The Relationship between Risk Tolerance and Overconfidence in Investors
}

\begin{abstract}
It is an undeniable fact that many factors affect investment decisions in financial markets and because of this decision-making becomes more difficult. In general, the reasons that make decision-making difficult may be divided into two; the reasons originating from the investor himself and the others that are not originating from investor himself. The personal characteristics and the behaviours of individual investors are the most important factors that affecting the investment decision. The aim of this study is to determine the risk tolerance levels of individual investors and clearify the relations between the concept of overconfidence which effects risk tolerance levels. In this context, risk tolerance and overconfidence behavior of individual investors in Turkey have been investigated in detail. In the scope of this study, a survey has been conducted to 520 individual investors which are resident in İstanbul, Ankara and Izmir. According to analysis results, a meaningful relation is found between overconfidence and risk tolerance of investors. According to this, risk tolerance levels rise as the overconfidence level rises. Further in the study, risk tolerance is divided into components. The findings show that, there is a meaningful relation between overconfidence, investment and financial risks of investors, but none in between speculative risk and overconfidence.
\end{abstract}

Key Words: Behavioral Finance, Financial Decision Making, Investor Psychology, Risk Tolerance, Overconfidence. 


\section{Giriş}

Davranışsal finans; yatırımcıların kararlar alırken etkisi altında bulundukları bilişsel ve duygusal faktörleri hesaba katarak yatırımcı davranışlarını psikoloji, sosyoloji ve antropoloji bilimlerinden yararlanarak anlamlandırmaya çalışan disiplinler arası bir çalışma alanıdır. Geleneksel finansın temel varsayımı "homo economicus"a karşı davranışsal finansın temeline aldığ 1 "sınırlı rasyonellik" kavramı önem teşkil etmektedir. Sonuç olarak, yatırımcıların karar mekanizmaları, tecrübeleri ve gelişim potansiyelleri tarafından belirlenen "içsel faktörler" kadar etkiledikleri ve etkilendikleri "dışsal faktörler" tarafından da oluşmaktadır.

Yatırımcıların karar modellerinde kullandıkları girdiler genellikle dört başlık altında toplanmıştır. Bunlar; yatırımcıların hedefleri, zaman ufukları, finansal istikrarları ve risk toleranslarıdır. İlk üç unsurun objektif olma yönünden ölçüm yapılabilmesi kolay iken, risk toleransı sübjektiftir ve ölçüm yapılmasının zor olması itibariyle diğer unsurlardan ayrılmaktadır. Yatırımcının finansal kararlarında tercih edeceği risk miktarı, bireyin risk tolerans düzeyini de göstermektedir. Bir yatırımcının risk tolerans düzeyinin belirlenmesi çok önemlidir. Çünkü risk tolerans seviyesi belirlenmeden herhangi bir yatırım önerisinde bulunmak veya uzun dönemli bir yatırım stratejisi ortaya koymak mümkün görünmemektedir.

Aşırı güven; yargı psikolojisindeki en güçlü sonuçlardan biri olarak kabul edilmektedir. Aşırı güvenli yatırımcılar; kişisel yeteneklerinin ortalamanın üzerinde olduğunu, sahip oldukları bilgilerin önemli ve bu bilgiler sayesinde sonuçları kontrol edebileceklerini, iyi sonuçlanan olguları kendilerine atfettikleri, vuku bulabilecek olaylar karşısında aşırı iyimserlik göstermeleri gibi birçok etmeni bünyelerinde barındırmaktadır. Dolayısıyla, bu etmenler finansal kararlara da etki etmektedir.

$\mathrm{Bu}$ çalışmanın amacl; bireysel yatırımclarda karar alma mekanizmasının merkezinde yer alan "risk toleransı" konusu ile söz konusu tolerans düzeyine etki eden unsurlardan biri olan "aşırı güven" kavramının detaylı olarak incelenmesidir. 


\section{Teorik Çerçeve}

Çalışmanın bu bölümünde davranışsal finans, aşırı güven ve risk toleransı hakkında bilgiler sunulacaktır.

\section{Davranışsal Finans}

Davranışsal finans, bünyesinde barındırdığı duygusal süreçler ve bunların karar alma süreci üzerinde ne derece etkili olduğu da dahil olmak üzere, yatırımcıların düşünce kalıplarını anlamaya ve açıklamaya çalışmaktadır (Ricciardi, 2005, s.7). Davranışsal finansın yatırımcı davranışlarına yönelik bakış açısını Statman (1999) “Geleneksel finansta insanlar rasyonel, davranışsal finansta ise normaldir" sözü ile belki de en iyi şekilde ifade etmiştir. Kahneman ve Tversky özellikle deneye dayalı (sezgisel), çerçeveleme etkisi ve beklenti teorisi çalışmaları ile davranışsal iktisadın gelişmesine katkıda bulunmuşlardır (Dumludağ vd., 2015, s.45).

Davranışsal finansta önemli bir olgu da hevristik konusudur. Hevristik kavramı, özellikle Herbert Simon'un (1957) çalışmasıyla, psikolojinin içerisinde yer almış ve yeniden tanıtılmıştır. Simon bu çalışmasında, sınırlı bilgi işleme yeteneklerinden dolayı, insanların dünyanın basitleştirilmiş modellerini inşa etmek zorunda kaldıklarını savunmuştur. 1970'lerde Kahneman ve Tversky, olasılığa dayanan akıl yürütmedeki hataları açıklamak için, söz konusu kavramı ödünç almıştır (Gigerenzer, 1991, s.15). Hevristik kavramını açıklamak için Tversky ve Kahneman (1974), "İnsanlar, olasılıkları değerlendirmek ve değerleri daha basit yargısal olgularla öngörmek için karmaşık görevleri azaltan, sınırlı sayıda sezgisel kurallara güvenmektedir. Genel olarak bu sezgisel yöntemler oldukça yararlıdır, fakat bazen ciddi ve sistematik hatalara yol açarlar" ifadelerini kullanmışlardır.

Tversky ve Kahneman (1974) çalışmalarında, üç temel kısa yoldan bahsetmektedir. Bunlar; 1)Temsiliyet, 2) Mevcudiyet (Bulunma), 3) Düzeltme ve Demirleme kısayollarıdır.

Temsil edilebilirlik hevristiki, bir olgunun öznel olasılığını kendi kitlesi içinde temel yapısı ile benzer olması ve kendisini oluşturan sürecin belirgin özelliklerini yansıtması durumlarına göre belirlemektedir 
(Kahneman ve Tversky, 1972, s.430). Bulunabilirlik hevristiki, insanların bir olayın gerçekleşme ihtimalini, söz konusu olayın vuku bulma oranına göre tahmin etmesine yol açmaktadır (Laibson ve Zeckhauser, 1998, s.10). Dayanak kestirme yöntemi ise, bir değerin başlangıç noktası kabul edilerek içinde bulunulan duruma uyarlanmasıdır. Demirleme, "muhafazakârlık" ile de yakından ilgili bir konudur.

\section{Aşırı Güven}

Aşırı güven, yargı psikolojisindeki en güçlü sonuçlardan biri olarak görülmektedir (De Bondt ve Thaler, 1995). Aşırı güven, bireylerin almış oldukları kararların doğruluğunu ve sahip oldukları bilgilerin kesinliğini sistematik olarak fazla tahmin etmesi olarak tanımlanabilir (Dittrich vd., 2005, s.471). Aşırı güven literatürü, insanların bilgilerine kesin olarak inandıkları, kendi yeteneklerini diğerlerine göre daha yüksekte derecelendirdikleri ve aşırı iyimserliğe sahip olduklarını göstermiştir (Odean, 1998, s.1894). Aşırı güveni artıran özellikle üç olgu üzerinde durulmaktadir. Bunlar:

1. Yükleme önyargisı

2. Bilgi yanılsaması

3. Kontrol yanilsamasidir.

Kontrol Yanılsaması, kişilerin rastgele ve birbirinden bağımsız olarak gerçekleşen olayları denetleyebileceğine duyduğu inanç olarak adlandırılmaktadır (Feyyat, 2007/2018, s.161). Kontrol yanılsamasına teşvik eden temel özellikler ise seçim, sonuç dizgisi, bilgi, göreve aşinalık ve aktif katılım olarak sıralanmaktadır (Nofsinger, 2001, s.18). Bilgi Yanılsaması, aşırı güvenli yatırımcların kendilerine ulaşan bilgi sinyallerinin kesinliğini abartmalarını ifade etmektedir (Odean, 1998, s.1982). İnsanlar daha fazla bilgiyle, tahminlerinin doğruluğunun arttı̆̆ına inanma eğilimi göstermektedir. Bu durum her koşulda böyle olmayabilir. Bunun üç temel sebebi bulunmaktadır (Nofsinger, 2001, s.14-15):

1. Bazı bilgiler tahmin etmeye yardımcı olmayabileceği gibi yanlış bile yönlendirebilir.

2. Birçok insan bilgiyi yorumlayacak eğitime, deneyime ve beceriye sahip olmayabilir. 
3. İnsanlar yeni bilgileri eski kanılarını doğrulama yönünde yorumlama eğilimi göstermektedir. Kendine Atfetme, insanların başarılarını kendilerine başarısızlıklarını ise dış etkilere bağlama eğilimi göstermeleri olarak ifade edilebilir (Miller ve Ross, 1975, s.213). Bu durum literatürde "kendine atfetme", başka bir ifade ile "yükleme önyargısı" olarak yer bulmaktadır. Kendine atfetme önyargısı, genel olarak ticaret mahareti açısından giderek artan bir şekilde aşırı güvene neden olacaktır (Barber ve Odean, 2002, s.460).

\section{Risk Tolerans1}

Finansal bağlamda risk toleransı, bir kişinin finansal karar verirken seçtiği risk miktarıdır. Bir bakış açısına göre risk toleransı, bir kişinin yaşam süresi boyunca aynı kalan ve kan grubu gibi son derece belirli bir özelliktir (Roszkowski ve Davey, 2010, s.42-43). Risk toleransının, finansal davranışı şekillendirmedeki önemi evrensel olarak kabul görmektedir. Birçok ülkede finansal durum tespiti ve etik kurallar, finans danışmanlarının müşterilerini finansal ve kişisel olarak tanımalarını gerektirir. Çünkü yatırım önerilerinin bu tanımanın sonucunda yapılan değerlendirmeye "uygun" olması beklenir. Teoride; yatırımcının hedefleri, zaman ufku, likidite ihtiyaçları ve riskten kaçınma hakkında yeterli bir bilgi sahibi olmadan uygun yatırımlar önermek veya o yatırımcı için verimli uzun vadeli yatırım stratejileri inşa etmek mümkün değildir (Klement, 2018, s.1).

Finansal risk toleransının ölçüm ve değerlendirme sürecinde yararlanılan yaklaşımları üç ana başlık altında toplamak mümkündür (Ardehali vd., 2005, s.495-496):

1. Objektif Ölçütler: bireyin geçmişte verdiği yatırım kararları, kişinin risk alma konusunda gerçek manada nasıl hissedebileceğinin objektif bir ölçütü olabilir.

2. Sezgisel Kararlar: yatırımcının finansal risk toleransını tahmin etmek üzere demografik, sosyo-ekonomik ve hatta davranışsal faktörleri kullanmaktadır.

3. Sübjektif Değerlendirme: buradaki vurgu, yatırımcının risk algısı ve finansal risk alma konusunda nasıl hissettiği üzerinedir. 
Araştırmalar, risk tercihleri üzerindeki en büyük etkinin deneyimlerden ve etkileşim içerisinde olunan çevreden geldiğini göstermektedir. Temel olarak bir yatırımcının risk profiline etki eden unsurları üç kategoride siralamak mümkündür: (1) finansal risk almaya olan genetik yatkınlığı, (2) etkileşimde olunan insanlar ve onların görüşlere yaptığı etkileri ve (3) yaşam deneyimlerindeki koşullar (Klement, 2018, s.9). Araştırmalar göstermiştir ki risk algısı; beta, standart sapma veya varyans gibi teknik risk hesaplamalarından ziyade sezgisel risk kavramlarının bir fonksiyonudur (Roszkowski ve Davey, 2010, s.44). Geleneksel finansta risk; tek boyutlu, objektif ve makro odaklı olarak tanımlanırsa bunun tam tersi davranışsal bakış açısını ifade eder.

Akademik yazında da risk toleransı ile davranışsal finans boyutları arasındaki ilişkileri ortaya koyan çalışmalar bulunmaktadır. Örneğin; yatırımcıların risk toleranslarını, yatırımcı kişilikleri ve davranışsal finans profillerine göre belirlemeyi amaçlayan Dickason ve Ferreira (2018), Güney Afrika'da uluslararası bir yatırım şirketinin müşterisi olan 1.171 yatırımcıya anket uygulamışlardır. Çalışmalarında orta risk toleransına sahip yatırımcıların demirleme, pişmanlık, temsililik, aşırı güven ve kumarbaz yanılgısına düştükleri sonucuna ulaşmışlardır. Düşük risk toleransına sahip muhafazakâr yatırımcıların, zarardan kaçınma ve zihinsel muhasebe önyargısına maruz kaldıklarını; yüksek risk toleransına sahip yatırımcıların ise çoğunlukla öz-kontrol yanılgısına maruz kaldıklarını bulgulamışlardır. Menkhoff vd. (2005), 2002'de 117 Alman fon yöneticisi üzerinde yapmış oldukları bir çalışmada deneyimin aşırı güven, sürü davranışı ve risk alma davranışı üzerindeki etkisini incelemişlerdir. Bulgulara göre; sürü davranışı, risk alma ve aşırı güven deneyim ile birlikte azalmaktadır. Daha yüksek risk alma, daha yüksek derecede aşırı güven, daha düşük sürü davranışı veya daha düşük derecede riskten kaçınma ile açıklanabilir. McCannon vd. (2015), bireylerdeki finansal yeterliliğin, aşırı güvenin ve yatırımlara güvenmenin sonuçlarını ortaya koymak adına Şubat 2014'te, New York'ta bulunan özel bir üniversitede birtakım deneyler yapmışlardır. Sonuçlar, aşırı güven davranışının önemli bir belirleyici olduğunu göstermiştir. Özellikle, kendine güvenen bireyler, riski seven tercihlerde bulunmuşlardır. 


\section{Uygulama}

$\mathrm{Bu}$ bölümde çalışmanın amacı ve önemi, araştırmanın evreni ve örneklemi, yöntem ve hipotezler, araştırmada kullanılan ölçekler ve güvenirlikleri ile çalışmaya ait bulgu ve değerlendirmeler yer alacaktır.

\section{Çalışmanın Amacı ve Önemi}

Bu çalışmanın amacl; bireysel yatırımcılarda karar alma mekanizmasının merkezinde yer alan "risk toleransı" konusu ile söz konusu tolerans düzeyine etki eden unsurlardan biri olan "aşırı güven" kavramının detaylı olarak incelenmesidir. Çok yönlü bir araştırma ile bu ikili arasındaki ilişkinin ortaya konulması, çalışmanın önemini göstermektedir.

\section{Araştırmanın Evreni ve Örneklemi}

Araştırmanın evreni, finansal piyasalarda işlem yapan bireysel yatırımcılardır. Araştırmanın örneklemi ise İstanbul, İzmir ve Ankara' da bulunan finans piyasalarında işlem yapan bireysel yatırımcılardır. Söz konusu şehirlerin seçilmesinin nedeni, nüfus bileşimi yönünden araştırma evrenini daha iyi temsil edebilme özelliğinden kaynaklanmaktadır.

Merkezi Kayıt Kuruluşu'nun (MKK) Eylül 2017 verilerine göre; Borsa İstanbul'daki yatırımcı sayısı 1 milyon 47 bin olarak gerçekleşmiştir. Yatırımciların \%99'u yerli, \%1'i ise yabanc1 uyrukludur. Yabanc1 yatırımcıların işlem hacmindeki payı \%26, piyasa değerindeki payı ise \%65 olmuştur. Yerli yatırımcıların \%99,5'ini oluşturan bireysel yatırımcılar, yerli portföy değerinin $\% 52$ sini elinde bulundurmaktadır. Bireysel yatırımcıların yaklaşı \%32'si İstanbul, \%12'si Ankara ve \%10'u da İzmir'de ikamet etmektedir (MKK, Eylül 2017).

\section{Yöntem ve Hipotezler}

Araştırmada veri toplama yöntemi olarak anket tekniği tercih edilmiştir. Anket formları bireysel yatırımcılara, gerek yüz yüze gerekse elektronik 
olarak yöneltilmiş olup, analize dâhil edilen anket sayısı 520 adet olarak belirlenmiştir. Yaklaşık olarak 1.000 .000 olan yatırımcı sayısının \%54'ü, yani yaklaşık 540.000 yatırımcı söz konusu illerde yaşamaktadır. Araştırmada kabul edilebilir hata düzeyi 0,05 ve güven düzeyi 0,95 yeterli bulunmuştur. Örneklem hacmi hesaplamasında aşağıdaki formül kullanılmıştır (Bartlett vd., 2001, s.47-48):

$$
n=\frac{(t)^{2} *(\mathrm{p}) *(\mathrm{q})}{(d)^{2}} \quad n=\frac{(1,96)^{2} * 0,5 * 0,5}{(0,05)^{2}}=384
$$

Çalışma kapsamındaki değerlendirmeye alınan 520 adet anket, istatistiki açıdan yeterli bir sayıyı ifade etmektedir.

Çalışmada oluşturulan hipotez ve alternatif hipotezleri aşağıdaki gibidir:

\section{$\mathrm{H}_{\mathrm{A}}$ : Yatırımcıların aşırı güvenleri ile risk toleransları arasında anlamlı bir ilişki vardır.}

- Ha1: Yatırımciların aşırı güvenleri ile yatırım riskleri arasında anlamlı bir ilişki vardır.

- HA2: Yatırımcıların aşırı güvenleri ile finansal riskleri arasında anlamlı bir ilişki vardır.

- Haз:Yatırımcıların aşırı güvenleri ile spekülatif riskleri arasında anlamlı bir ilişki vardır.

\section{Araştırmada Kullanılan Ölçekler ve Güvenirlikleri}

Çalışma kapsamındaki anket demografik özelliklerin belirlenmesine yönelik soruların yanı sıra, finansal risk toleransını ölçmeye yönelik 13 adet ve aşırı güven davranışını ölçmeye yönelik 14 adet olmak üzere toplamda 36 adet sorudan oluşmaktadır. Anket kapsamındaki sorular arasında çoktan seçmeli sorular ve 5'li Likert Ölçekli sorular bulunmaktadır.

Risk toleransını belirlemeye yönelik ölçek, Grable ve Lytton (1999a) tarafından gerçekleştirilen "Financial Risk Tolerance Revisited: The Development of a Risk Assessment Instrument" adlı çalışmada kullanılan ölçektir. 13 maddelik çoktan seçmeli soruyu içeren ölçek, bireysel yatırımcıların risk toleransını yatırım riski, finansal risk ve spekülatif risk bileşenleri bağlamında ölçmektedir. Bireysel 
yatırımcıların aşırı güven eğilimini ölçmek üzere oluşturulan maddeler ise Langer ve Roth (1975), Miller ve Ross (1975), Svenson (1981), Odean (1998), Barber ve Odean (2000), Nofsinger (2001) ve Pompian (2006) tarafından gerçekleştirilen çalışmalar incelenerek hazırlanmıştır.

Bu çalışmada, ölçeklerin güvenirliğini test etmede "Cronbach's Alfa" kullanılmıştır. Güvenirlik analizlerinde alfa katsayısının değerlendirilmesinde göz önünde bulundurulan kriter (a) $0.00 \leq \alpha<0.40$ ise ölçek güvenilir değildir, (b) $0.40 \leq \alpha<0.60$ ise ölçek düşük güvenilirliktedir, (c) $0.60 \leq \alpha<0.80$ ise ölçek oldukça güvenilirdir, (d) $0.80 \leq \alpha<1.00$ ise ölçek yüksek derecede güvenilir bir ölçektir (Özdamar, 1999, s.522). Analiz sonucunda 13 maddelik risk tolerans ölçeğine ait Cronbach's Alfa değeri 0,514 olarak, 14 maddelik aşırı güven ölçeğine ait Cronbach's Alfa değeri ise 0,857 olarak belirlenmiştir.

\section{Bulgular}

Çalışmanın bu bölümünde aşırı güven davranışına, risk toleransına ve aşırı güven ile risk toleransı arasındaki ilişkiye dair bulgular ve değerlendirmeler bulunmaktadır. Bu çalışmaya ilişkin veriler 2019 yılı Nisan, Mayıs ve Haziran aylarında toplanmıştır.

\section{Aşırı Güven Davranışına İlişkin Bulgu ve Değerlendirme}

Çalışmanın bu bölümünde katılımcıların aşırı güven düzeyleri ifade edilecek ve söz konusu düzeylere göre dağılımları Tablo 1'de gösterilmiştir.

Tablo 1.Yatırımcıların Aşırı Güven Düzeyleri

\begin{tabular}{llll}
\hline Aşırı Güven Düzeyi & Puan Aralığı & Frekans & Yüzde \\
\hline Düşük & $19-42$ & 176 & 33,8 \\
Orta & $42,1-49,99$ & 164 & 31,5 \\
Yüksek & $50-70$ & 180 & 34,6 \\
Toplam & & 520 & 100 \\
\hline
\end{tabular}

5'li likert ölçekte yer alan 14 maddelik aşırı güven ifadesine 520 yatırımcının her birinin vermiş olduğu cevaplara göre bir değer oluşturulmuştur. Buna göre, tabloda belirtilen puan aralıklarında 176 
kişi düşük düzeyde, 164 kişi orta düzeyde ve 180 kişi ise yüksek düzeyde aşırı güvenli kategorisinde toplanmıştır.

\section{Risk Toleransına Yönelik Bulgu ve Değerlendirmeler}

Çalışmanın bu bölümünde öncelikle risk tolerans ölçeğine ait maddelerin seçeneklerine göre atfedilen puanlar yer alacaktır. Daha sonra, bu puan aralıklarına göre risk düzeyleri ifade edilecek ve bu çalışmaya katılan bireysel yatırımcıların risk düzeylerine göre dağılımları sunulacaktır.

Bireysel yatırımciların risk tolerans puanlarının belirlenmesinde Grable ve Lytton'ın (1999b, s.3) her bir maddedeki seçenekler için atadığ1 değerler kullanılmıştır. Söz konusu değerler Tablo 2'de gösterildiği gibidir.

\section{Tablo 2. Risk Toleransı Maddelerine Yönelik Cevapların Puanları}

\begin{tabular}{lllll}
\hline Sorular & A & B & C & D \\
\hline $\mathbf{1}$ & 4 & 3 & 2 & 1 \\
$\mathbf{2}$ & 1 & 2 & 3 & 4 \\
3 & 1 & 2 & 3 & 4 \\
$\mathbf{4}$ & 1 & 2 & 3 & - \\
$\mathbf{5}$ & 1 & 2 & 3 & - \\
$\mathbf{6}$ & 1 & 2 & 3 & 4 \\
$\mathbf{7}$ & 1 & 2 & 3 & 4 \\
$\mathbf{8}$ & 1 & 2 & 3 & 4 \\
$\mathbf{9}$ & 1 & 3 & - & - \\
$\mathbf{1 0}$ & 1 & 3 & - & - \\
$\mathbf{1 1}$ & 1 & 2 & 3 & - \\
$\mathbf{1 2}$ & 1 & 2 & 3 & 4 \\
$\mathbf{1 3}$ & 1 & 2 & 3 &
\end{tabular}

Kaynak: Grable ve Lytton, 1999b, s.3

Anket çalışmasına katılan her bir yatırımcının verdiği cevapların puanları toplandığında bir "Risk Tolerans Skoru" elde edilmektedir. Buna göre ulaşılabilecek en düşük risk tolerans puanı 13, en yüksek risk tolerans puanı ise 47 olarak belirmektedir. Bu skorlar, Grable ve Lytton (1999b, s.3) tarafından 5 farklı risk kategorisinde ifade edilmiştir. Puan aralıklarına göre risk kategorileri Tablo 3 'de gösterildiği gibidir. 
Tablo 3. Puan Aralıklarına Göre Yatırımcıların Risk Düzeyleri

\begin{tabular}{lll}
\hline Risk Düzeyi & Puan Aralı̆̆1 & Kodu \\
\hline Düşük Risk Toleransı (Muhafazakâr Yatırımcı Tipi) & 18 ve Altı & RD1 \\
Ortalama Altında Risk Toleransı & $19-22$ & RD2 \\
Orta Düzeyde Risk Toleransı & $23-28$ & RD3 \\
Ortalama Üzeri Risk Toleransı & $29-32$ & RD4 \\
Yüksek Risk Toleransı (Agresif Yatırımcı Tipi) & 33 ve Üzeri & RD5 \\
\hline
\end{tabular}

Kaynak: Grable ve Lytton, 1999b, s.3

Tablo 3'de Grable ve Lytton (1999b) tarafından oluşturulan puan aralıkları, bu aralıklara göre konumlandırılan yatırımcıların risk tolerans düzeyleri ve bu çalışmaya özgü türetilmiş kodlar yer almaktadır. Çalışmanın devamında oluşturulacak tablolarda risk düzeyleri, Tablo 3'de belirtilen kodlar ile ifade edilecektir.

Tablo 4.Bireysel Yatırımcıların Risk Düzeylerine Göre Dağılımları

\begin{tabular}{llll}
\hline RİSK DÜZEYİ & PUAN ARALIĞI & FREKANS & YÜZDE \\
\hline RD1 & 18 ve Alt1 & 13 & 2,5 \\
RD2 & $19-22$ & 47 & 9 \\
RD3 & $23-28$ & 218 & 41,9 \\
RD4 & $29-32$ & 164 & 31,5 \\
RD5 & 33 ve Üzeri & 78 & 15 \\
TOPLAM & & 520 & 100 \\
\hline
\end{tabular}

Tablo 4'te, bireysel yatırımcıların risk tolerans düzeylerine göre sinıflandırması yer almaktadır. Buna göre en büyük topluluğu $(\% 41,9)$ orta düzeyde risk toleransına sahip grup oluşturmaktadır. Ortalama üzeri risk toleransına sahip grup $(\% 31,5)$ ikinci büyük topluluğu ifade ederken, bu sıralamayı yüksek risk tolerans düzeyine sahip grup (\%15) izlemektedir.

\section{Aşırı Güven ve Risk Toleransı Arasındaki İlişkinin Ki-Kare Analizi (Risk Tolerans Düzeylerine Göre)}

Çalışmanın bu bölümünde, bireysel yatırımcıların aşırı güvenleri ile risk toleransları arasındaki ilişki incelenmiştir. Söz konusu ilişki incelenirken, üç düzeye ayrılan aşırı güvenin (düşük, orta ve yüksek) risk tolerans düzeyleri (düşük, ortalama altı, orta, ortalama üzeri ve yüksek) üzerindeki etkisi araştırılmıştır. Çalışmanın analiz edilmesinde verilere ki-kare testi uygulanmıştır. Kullanılan değerlerin kategorik bir şekilde ve 
grupların da birbirinden bağımsız olması nedeniyle, söz konusu analiz tercih edilmiştir.

"HA: Yatırımcıların aşırı güvenleri ile risk toleransları arasında anlamlı bir ilişki vardır." Buna göre kurulan hipotezler şu şekildedir:

Ho: Yatırımcıların aşırı güvenleri ile risk toleransları arasında farklılık yoktur.

$H_{1}$ : Yatırımcıların aşırı güvenleri ile risk toleransları arasında farklılık vardir.

Tablo 5. Aşırı Güven ve Risk Tolerans Düzeyleri Arasındaki İlişkinin Ki-Kare Analizi

\begin{tabular}{llllllll}
\hline AŞIRI & GÜVEN & \multicolumn{7}{l}{ RİSK TOLERANS DÜZEYLERं (\%) } & & \\
\cline { 2 - 7 } DÜZEYI & RD1 & RD2 & RD3 & RD4 & RD5 & $\chi^{2}$ & P \\
\hline Düşük & 61,5 & 59,6 & 40,8 & 21,3 & 20,5 & & \\
Orta & 23,1 & 17 & 29,8 & 37,8 & 33,3 & 42,391 & $\mathbf{0 , 0 0 0}$ \\
Yüksek & 15,4 & 23,4 & 29,4 & 40,9 & 46,2 & & \\
\hline
\end{tabular}

Not: $R D 1, R D 2, R D 3, R D 4$ ve RD5 risk tolerans düzeylerinin düş̈̈kten yükseğe doğru stralamasinu ifade etmektedir.

Tablo 5'de, yatırımcıların aşırı güvenleri ile risk tolerans düzeyleri arasında $\chi^{2}$ istatistik değerine bağlı olasılık değeri p: 0,000<0,05 olduğu için istatistiksel olarak anlamlı bir ilişkiden söz edilebilir. Başka bir ifadeyle, aşırı güven düzeyleri ile risk tolerans düzeyleri birbiriyle bağımlıdır. Çünkü yokluk hipotezi $\mathrm{H}_{0}$ reddedilebilir ve “ $\mathrm{H}_{1}$ : Yatırımcıların aşırı güvenleri ile risk toleransları arasında farklılık vardır" hipotezi kabul edilebilir.

\section{Aşırı Güven ve Risk Toleransı Arasındaki İlişkinin Ki-Kare Analizi (Risk Tolerans Bileşenlerine Göre)}

Grable vd. (2011, s.488) çalışmalarında, 13 maddeli risk tolerans ölçeğini başlıca üç kategoriye ayırmışlardır. Yazarlara göre 4, 5, 8, 11 ve 12. maddeler yatırım; 1, 3, 6, 7 ve 13. maddeler finansal ve 2, 9 ve 10 . maddeler ise spekülatif riski ölçmektedir. Çalışmanın devamında, aşırı güven düzeylerinin (düşük, orta ve yüksek) risk toleransını oluşturan bileşenlere (yatırım riski, finansal risk ve spekülatif risk) etkileri incelenecektir. $\mathrm{Bu}$ bağlamda her bir bileşeni oluşturan maddeler 
(ifadeler) ile aşırı güveni oluşturan düzeyler ki-kare analizine tabi tutularak hipotezler test edilecektir.

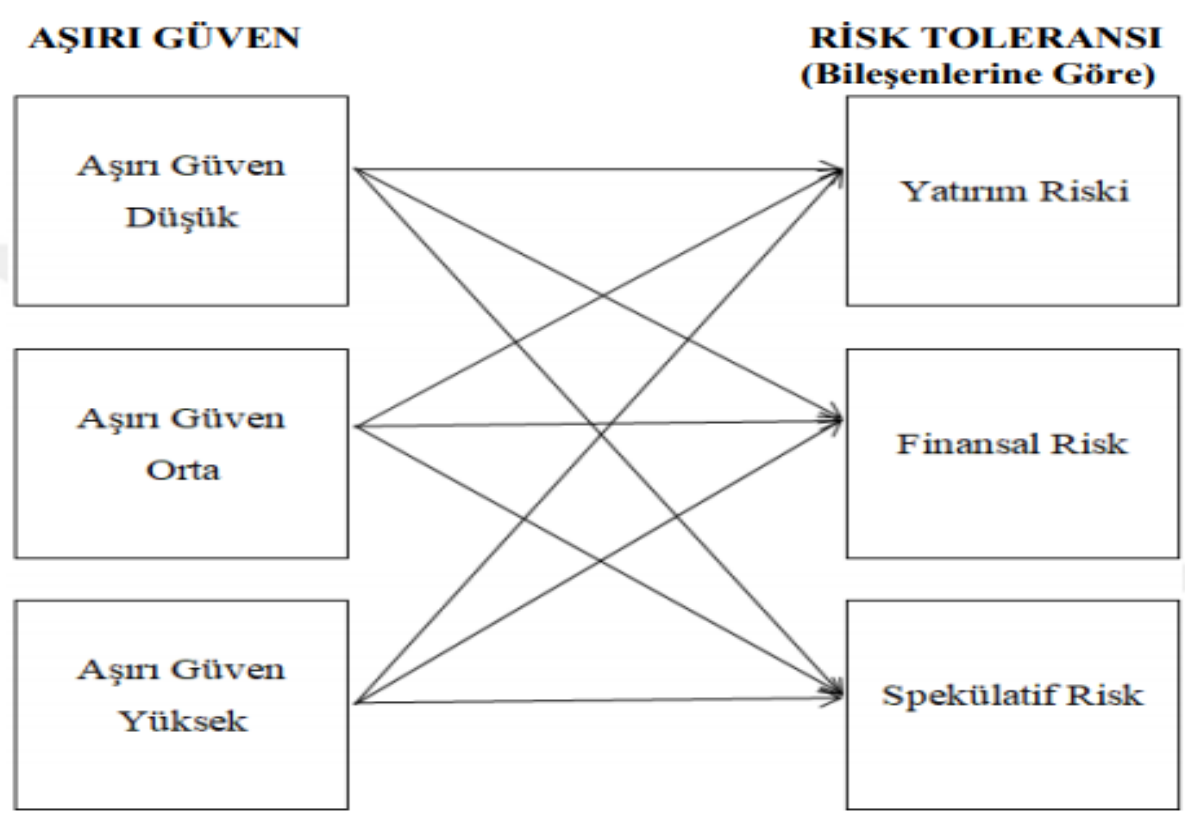

Şekil 1. Aşırı Güven ve Risk Tolerans Bileşenleri Arasındaki İlişki Modeli

Yatırımcıların aşırı güven düzeyleri ile risk toleransını meydana getiren risk bileşenleri arasındaki ilişkiyi incelemek üzere yukarıda yer alan Şekil 1'deki model oluşturulmuştur.

\section{Aşırı güven ve yatırım riski arasındaki ilişkinin Ki-Kare analizi}

Çalışmanın bu bölümünde, yatırımcıların aşırı güvenleri ile yatırım riski arasındaki ilişki ki-kare testi ile analiz edilecektir. Bunun için yatırım riskini oluşturan ifadelerden sırasıyla dördüncü, beşinci, sekizinci, onbirinci ve onikinci maddeler analize tabi tutulmuştur.

"HA1: Yatırımcıların aşırn güvenleri ile yatırım riskleri arasında anlamlı bir ilişki vardır." Buna göre kurulan hipotezler şu şekildedir:

Ho: Yatırımcılarm aşırı güvenleri ile yatırım riskleri arasında farklılık yoktur. 
H1: Yatırımcıların aşırı güvenleri ile yatırım riskleri arasında farklılık vardır.

Tablo 6. Aşırı Güven ve Yatırım Riski Arasındaki İlişki - (Madde 4'e Göre)

\begin{tabular}{|c|c|c|c|c|c|}
\hline \multirow{3}{*}{$\begin{array}{l}\text { Assırı } \\
\text { Güven }\end{array}$} & \multicolumn{5}{|c|}{ Yatırım Riski (\%) (Risk Tolerans Ölçeği Madde 4) } \\
\hline & \multicolumn{5}{|c|}{$\begin{array}{l}\text { Yatırım yapmak üzere beklenmedik bir şekilde } 20.000 \text { TL elde etseydiniz, ne } \\
\text { yapardınz? }\end{array}$} \\
\hline & $\begin{array}{l}\text { Banka mevduatına veya } \\
\text { para piyasasına yatırırdım }\end{array}$ & $\begin{array}{l}\text { Güvenilir, yüksek kaliteli } \\
\text { tahvillere veya hazine } \\
\text { bonosuna yatırırdım. }\end{array}$ & $\begin{array}{l}\text { Hisse senedine yatırım } \\
\text { yapardım }\end{array}$ & $\chi^{2}$ & $\mathrm{p}$ \\
\hline Düşük & 59,1 & 50 & 14,7 & & \\
\hline Orta & 29,6 & 20,8 & 34,6 & 123,73 & 0,00 \\
\hline Yükse & & & & 3 & 0 \\
\hline $\mathrm{k}$ & 11,3 & 29,2 & 50,7 & & \\
\hline
\end{tabular}

Tablo 6'daverilen cevaplara göre, p: 0,000<0,05 olduğu için;" $H_{0}$ : Yatırımcıların aşırı güvenleri ile yatırım riskleri arasında farklılık yoktur" hipotezi reddedilip, "H1: Yatırımclların aşırı güvenleri ile yatırım riskleri arasında farklllık vardır" hipotezi kabul edilmiştir.

Tablo 7. Aşırı Güven ve Yatırım Riski Arasındaki İlişki - (Madde 5'e Göre)

\begin{tabular}{|c|c|c|c|c|c|}
\hline \multirow{3}{*}{$\begin{array}{l}\text { Aşırı } \\
\text { Güven }\end{array}$} & \multicolumn{5}{|c|}{ Yatırım Riski (\%) (Risk Tolerans Ölçeği Madde 5) } \\
\hline & \multicolumn{5}{|c|}{$\begin{array}{l}\text { Deneyimlerinize dayanarak hisse senetleri ve yatırım fonlarına yatırım yaparken kendinizi ne } \\
\text { kadar rahat hissedersiniz? }\end{array}$} \\
\hline & Pek rahat hissetmem & Biraz rahat hissederim & Çok rahat hissederim & $\chi^{2}$ & $\mathrm{P}$ \\
\hline Düşük & 48,5 & 27 & 14,7 & & \\
\hline Orta & 22,5 & 41,1 & 23,5 & 54,552 & 0,000 \\
\hline Yüksek & 28,9 & 31,9 & 61,8 & & \\
\hline
\end{tabular}

Tablo 7'de yer alan ifadelerin sonucuna göre, p: 0,000<0,05 değeri elde edilmiştir. Buna göre "Ho: Yatırımcıların aşırı güvenleri ile yatırım riskleri arasında farklılı yoktur" hipotezi reddedilmiş, "H1: Yatırımciların aşırı güvenleri ile yatırım riskleri arasında farklılı vardır" hipotezi kabul edilmiştir.

Tablo 8. Aşırı Güven ve Yatırım Riski Arasındaki İlişki - (Madde 8'e Göre)

\begin{tabular}{|c|c|c|c|c|c|c|}
\hline \multirow[b]{3}{*}{$\begin{array}{l}\text { Aşırı } \\
\text { Güven }\end{array}$} & \multicolumn{6}{|c|}{ Yatırım Riski (\%) (Risk Tolerans Ölçeği Madde 8) } \\
\hline & \multicolumn{6}{|c|}{ Aşağıda belirtilen dört yatırım seçeneğinde, en iyi ve en kötü getiri seçenekleri yer almaktadır. Hangisini tercih edersiniz? } \\
\hline & $\begin{array}{l}\text { En iyi ihtimalle } 200 \mathrm{TL} \\
\text { kazanç; en kötü ihtimalle } \\
0 \text { TL kayıp }\end{array}$ & $\begin{array}{l}\text { En iyi ihtimalle } 800 \mathrm{TL} \\
\text { kazanç; en kötü } \\
\text { ihtimalle } 200 \text { TL kayıp }\end{array}$ & $\begin{array}{l}\text { En iyi ihtimalle } 2.600 \mathrm{TL} \\
\text { kazanç; en kötü } \\
\text { ihtimalle } 800 \text { TL kayıp. }\end{array}$ & $\begin{array}{l}\text { En iyi ihtimalle } 4.800 \\
\text { TL kazanç; en kötü } \\
\text { ihtimalle } 2.400 \quad \mathrm{TL} \\
\text { kayıp }\end{array}$ & $\chi^{2}$ & $\mathrm{p}$ \\
\hline Düşük & 35,9 & 31,5 & 33,1 & 40 & & \\
\hline Orta & 29,5 & 31 & 35,5 & 25,7 & 3,945 & 0,684 \\
\hline Yüksek & 34,6 & 37,5 & 31,4 & 34,3 & & \\
\hline
\end{tabular}


Tablo 8'deyer alan ifadenin sonucuna göre, p: 0,684>0,05 olduğu için "Ho: Yatırımcıların aşırı güvenleri ile yatırım riskleri arasında farklılık yoktur" hipotezi kabul edilmiştir.

Tablo 9. Aşırı Güven ve Yatırım Riski Arasındaki İlişki - (Madde 11'e Göre)

\begin{tabular}{|c|c|c|c|c|c|c|}
\hline \multirow{3}{*}{$\begin{array}{l}\text { Aşırı } \\
\text { Güven }\end{array}$} & \multicolumn{6}{|c|}{ Yatırım Riski (\%) (Risk Tolerans Ölçeği Madde 11) } \\
\hline & \multicolumn{6}{|c|}{$\begin{array}{l}\text { Bir akrabanızdan size } 100.000 \text { TL miras kaldığını düşünün. Ancak mirasın TAMAMINI aşağıdaki } \\
\text { seçeneklerden yalnızca BİRİNE yatırmanız gerekmektedir. Hangisini tercih ederdiniz? }\end{array}$} \\
\hline & $\begin{array}{l}\text { Bir tasarruf } \\
\text { hesabına veya } \\
\text { para piyasasına }\end{array}$ & $\begin{array}{l}\text { Hisse senedi ve tahvil } \\
\text { içeren bir yatırım } \\
\text { fonuna }\end{array}$ & $\begin{array}{l}15 \text { hisse } \\
\text { senedinden } \\
\text { oluşan bir } \\
\text { portföy }\end{array}$ & $\begin{array}{l}\text { Altın, gümüş ve } \\
\text { petrol gibi } \\
\text { emtialara }\end{array}$ & $\chi^{2}$ & $\mathrm{p}$ \\
\hline Düşük & 54,3 & 27,8 & 17,5 & 36,8 & & \\
\hline Orta & 26,5 & 30,5 & 34,4 & 34,2 & 58,260 & 0,000 \\
\hline Yüksek & 19,2 & 41,7 & 48,1 & 28,9 & & \\
\hline
\end{tabular}

Tablo 9'da belirtilen ifadenin sonucuna göre, p: 0,000<0,050 değeri elde edilmiştir. Bu bağlamda $H_{0}$ hipotezi reddedilip, " $H_{1}$ : Yatırımcıların aşırı güvenleri ile yatırım riskleri arasında farklılık vardır" hipotezi kabul edilmiştir.

Tablo 10. Aşırı Güven ve Yatırım Riski Arasındaki İlişki - (Madde 12'ye Göre)

\begin{tabular}{|c|c|c|c|c|c|}
\hline \multirow{3}{*}{$\begin{array}{l}\text { Aşırı } \\
\text { Güven }\end{array}$} & \multicolumn{5}{|c|}{ Yatırım Riski (\%) (Risk Tolerans Ölçeği Madde 12) } \\
\hline & \multicolumn{5}{|c|}{$\begin{array}{l}20.000 \text { TL'lik bir yatırım yapma durumunuzda, aşağıdakilerden hangisi sizin için en cazip } \\
\text { seçenek olurdu? }\end{array}$} \\
\hline & $\begin{array}{l}\text { \%60 düşük riskli } \\
\text { yatırımlar; \%30 orta riskli } \\
\text { yatırımlar; \%10 yüksek } \\
\text { riskli yatırımlar }\end{array}$ & $\begin{array}{l}\text { \%30 düşük riskli } \\
\text { yatırımlar; } \% 40 \text { orta riskli } \\
\text { yatırımlar; } \% 30 \text { yüksek } \\
\text { riskli yatırımlar }\end{array}$ & $\begin{array}{l}\text { \%10 düşük riskli } \\
\text { yatırımlar; } \% 40 \text { orta riskli } \\
\text { yatırımlar; } \% 50 \text { yüksek } \\
\text { riskli yatırımlar }\end{array}$ & $\chi^{2}$ & $\mathrm{p}$ \\
\hline Düşük & 41,8 & 26,1 & 30 & & \\
\hline Orta & 29,1 & 37,6 & 16 & 23,469 & 0,000 \\
\hline Yüksek & 29,1 & 36,3 & 54 & & \\
\hline
\end{tabular}

Tablo 10'da belirtilen ifadelerin sonucunda, p: 0,000<0,050 değerine ulaşılmıştır. Buna göre $H_{0}$ hipotezi reddedilip, "H1: Yatırımcıların aşırı güvenleri ile yatırım riskleri arasında farklılı vardır" hipotezi kabul edilmiştir.

Özet olarak; tüm değerlendirmeler göz önünde bulundurulduğunda "HA1: Yatırımolların aşırı güvenleri ile yatırım riskleri arasında anlamlı bir ilişki vardır" hipotezi kabul edilmiştir. 


\section{Aşırı güven ve finansal risk arasındaki ilişkinin Ki-Kare analizi}

Çalışmanın bu bölümünde, yatırımcıların aşırı güvenleri ile finansal riskleri arasındaki ilişki ki-kare testi ile analiz edilecektir. Bunun için finansal riski oluşturan ifadelerden sırasıyla birinci, üçüncü, altıncı, yedinci ve onüçüncü maddeler analize tabi tutulmuştur.

"HA2: Yatırnmcılarn aşın güvenleri ile finansal riskleri arasında anlamlı bir ilişki vardır." Buna göre kurulan hipotezler şu şekildedir:

Ho: Yatırımcıların aşırı güvenleri ile finansal riskleri arasında farklılık yoktur.

H1: Yatırımcıların aşırı güvenleri ile finansal riskleri arasında farklılık vardir.

Tablo 11. Aşırı Güven ve Finansal Risk Arasındaki İlişki - (Madde 1'e Göre)

\begin{tabular}{|c|c|c|c|c|c|c|c|}
\hline \multirow{3}{*}{ Aşırı Güven } & \multicolumn{7}{|c|}{ Finansal Risk (\%) (Risk Tolerans Ölçeği Madde 1) } \\
\hline & \multicolumn{7}{|c|}{ Genel anlamda risk alma açısından, en iyi arkadaşınız sizi nasıl tanımlar? } \\
\hline & $\begin{array}{l}\text { Gerçek } \\
\text { kumarbaz }\end{array}$ & bir & $\begin{array}{l}\text { Araştırmalardan sonra } \\
\text { risk almaya istekli }\end{array}$ & Tedbirli & $\begin{array}{l}\text { Riskten } \\
\text { kaçınan }\end{array}$ & $x^{2}$ & $\mathrm{p}$ \\
\hline Düşük & 7,7 & & 33,8 & 33,7 & 85,7 & & \\
\hline Orta & 46,1 & & 32,7 & 30,5 & 0 & 12,999 & 0,043 \\
\hline Yüksek & 46,2 & & 33,5 & 35,8 & 14,3 & & \\
\hline
\end{tabular}

Tablo 11'de yer alan ifadenin sonucuna göre p: 0,043<0,050 değeri elde edilmiştir. Bu nedenle $H_{0}$ hipotezi reddedilip, " $\mathrm{H}_{1}$ : Yatırımcıların aşırı güvenleri ile finansal riskleri arasinda farklılık vardır" hipotezi kabul edilmiştir.

Tablo 12. Așırı Güven ve Finansal Risk Arasındaki İlişki - (Madde 3'e Göre)

\begin{tabular}{|c|c|c|c|c|c|c|}
\hline \multirow{3}{*}{$\begin{array}{l}\text { Aşırı } \\
\text { Güven }\end{array}$} & \multicolumn{6}{|c|}{ Finansal Risk(\%) (Risk Tolerans Ölçeği Madde 3) } \\
\hline & \multicolumn{6}{|c|}{$\begin{array}{l}\text { Hayatınızda sadece bir kere" yapabileceğiniz bir tatil için para biriktirdiniz. Fakat planladığınız tatile çıkmadan üç } \\
\text { hafta önce işinizi kaybediyorsunuz. Ne yaparsınız? }\end{array}$} \\
\hline & $\begin{array}{l}\text { Tatili iptal } \\
\text { ederim. }\end{array}$ & $\begin{array}{l}\text { Daha } \\
\text { mütevazı bir } \\
\text { tatile çıarım. }\end{array}$ & $\begin{array}{l}\text { Yeni bir iş arama sürecinde } \\
\text { zamana ihtiyacım olacağını } \\
\text { düşünerek, planladığım tatile } \\
\text { çıarım. }\end{array}$ & $\begin{array}{l}\text { Daha kapsamlı bir tatil } \\
\text { yaparım. Çünkü böyle } \\
\text { birinci sınıf bir tatil için, bu } \\
\text { son şansım olabilir }\end{array}$ & $x^{2}$ & $\mathrm{p}$ \\
\hline Düşük & 32,2 & 39,5 & 32,3 & 31 & & \\
\hline Orta & 32,2 & 26,9 & 34,2 & 31 & 2,911 & 0,82 \\
\hline Yüksek & 35,6 & 33,6 & 33,5 & 37,9 & & \\
\hline
\end{tabular}

Tablo 12'de sunulan ifadelerin sonucuna göre, p: 0,820>0,050 olduğu için "Ho: Yatırımcıların aşırı güvenleri ile finansal riskleri arasında farklılık yoktur" hipotezi kabul edilmiştir. Diğer bir ifadeyle, bu maddeye göre 
yatırımcıların aşırı güvenleri ile finansal riskleri arasında bir ilişki mevcut değildir.

Tablo 13. Aşırı Güven ve Finansal Risk Arasındaki İlişki - (Madde 6'ya Göre)

\begin{tabular}{|c|c|c|c|c|c|c|}
\hline \multirow{3}{*}{ Aşırı Güven } & \multicolumn{6}{|c|}{ Finansal Risk (\%) (Risk Tolerans Ölçeği Madde 6) } \\
\hline & \multicolumn{6}{|c|}{ "Risk" kelimesini düşündüğünüzde aklınıza ilk gelen kelime hangisidir? } \\
\hline & Kayıр & Belirsizlik & Firsat & Heyecan & $\chi^{2}$ & $\mathrm{p}$ \\
\hline Düşük & 33,8 & 40 & 22,2 & 39,7 & & \\
\hline Orta & 29,7 & 30,4 & 33,3 & 33,3 & 16,801 & 0,01 \\
\hline Yüksek & 36,5 & 29,6 & 44,4 & 27 & & \\
\hline
\end{tabular}

Tablo 13'te yer alan ifadenin sonucuna göre, p: 0,01<0,050 değer elde edilmiştir. Bu bağlamdaHohipotezi reddedilip, "H1: Yatırımcıların aşırı güvenleri ile finansal riskleri arasında farklılı vardır" hipotezi kabul edilmiştir.

Tablo 14. Aşırı Güven ve Finansal Risk Arasındaki İlişki - (Madde 7'ye Göre)

\begin{tabular}{|c|c|c|c|c|c|c|}
\hline \multirow[b]{3}{*}{$\begin{array}{l}\text { Aşırı } \\
\text { Güven }\end{array}$} & \multicolumn{6}{|c|}{ Finansal Risk (\%) (Risk Tolerans Ölçeği Madde 7) } \\
\hline & \multicolumn{6}{|c|}{$\begin{array}{l}\text { Bazı uzmanlar, fiziki varlıkların değerinin artacağını, tahvil fiyatlarının düşebileceğini, bununla } \\
\text { birlikte devlet tahvillerinin görece olarak daha güvenli olduğunu düşünmektedir. Şu anda yüksek } \\
\text { faizli devlet tahvillerinde yatırımlarınız bulunmaktadır. Bu durumda ne yapardınız? }\end{array}$} \\
\hline & $\begin{array}{l}\text { Tahvilleri } \\
\text { elimde } \\
\text { tutardım. }\end{array}$ & $\begin{array}{l}\text { Tahvilleri satar, } \\
\text { paranın yarısını para } \\
\text { piyasası araçlarında, } \\
\text { diğer yarısını ise fiziki } \\
\text { varlıklarda } \\
\text { değerlendirirdim }\end{array}$ & $\begin{array}{l}\text { Tahvilleri satar } \\
\text { ve hasılatın } \\
\text { tamamını fiziki } \\
\text { varlıklarda } \\
\text { değerlendirirdim }\end{array}$ & $\begin{array}{l}\text { Tahvilleri satar ve hasılatın } \\
\text { tamamını fiziki varlıklara } \\
\text { yatırır, bunlara ek olarak } \\
\text { daha fazla yatırım yapmak } \\
\text { için kredi alırdım. }\end{array}$ & $\chi^{2}$ & $\mathrm{p}$ \\
\hline Düşük & 36,4 & 30,9 & 37,2 & 40 & & \\
\hline Orta & 31,5 & 32,5 & 32,1 & 13,3 & 4,616 & 0,594 \\
\hline Yüksek & 32,1 & 36,6 & 30,8 & 46,7 & & \\
\hline
\end{tabular}

Tablo 14 'te bulunan ifadenin sonucuna göre, p: 0,594>0,050 olduğu için "Ho: Yatırımciların aşırı güvenleri ile finansal riskleri arasında farklllık yoktur" hipotezi kabul edilmiştir. Başka bir ifadeyle, bu maddeye göre yatırımcıların aşırı güvenleri ile finansal riskleri arasında bir ilişki bulunmamaktadir.

Tablo 15. Aşırı Güven ve Finansal Risk Arasındaki İlişki - (Madde 13'e Göre)

\begin{tabular}{ll}
\hline \multirow{3}{*}{ Aşırı Güven } & Finansal Risk (\%) (Risk Tolerans Ölçeği Madde 13) \\
\cline { 2 - 3 } & $\begin{array}{l}\text { Güvendiğiniz uzman bir jeolog arkadaşınız “altın madeni arama” girişimine finansman } \\
\text { sağlamak üzere, bir grup yatırımcıyı bir araya getiriyor. Eğer girişim başarılı olursa, } 50 \text { ila } 100 \\
\text { kat arası kazanç getirecektir. Fakat başarısız olursa, tüm yatırım batacaktır. Arkadaşınız ise } \\
\text { başarı şansını yalnızca \%20 olarak görmektedir. Eğer paranız olsaydı, ne kadarını yatırım }\end{array}$ \\
\hline
\end{tabular}




\begin{tabular}{|c|c|c|c|c|c|c|}
\hline \multirow[b]{3}{*}{ Düşük } & \multicolumn{6}{|l|}{ yapardınız? } \\
\hline & $\begin{array}{l}\text { Hiçbir şey } \\
\text { yatırmazdım }\end{array}$ & $\begin{array}{l}\text { Bir aylık } \\
\text { maaşımı } \\
\text { yatırırdım. }\end{array}$ & $\begin{array}{ll}\text { Üç } & \text { aylık } \\
\text { maaşımı } & \\
\text { yatırırdım } & \end{array}$ & $\begin{array}{l}\text { Altı aylık maaşımı } \\
\text { yatırırdım }\end{array}$ & $\chi^{2}$ & $\mathrm{p}$ \\
\hline & 42,2 & 34,3 & 25,5 & 19,4 & & \\
\hline Orta & 27,2 & 33,1 & 34,9 & 29 & 12,942 & 0,044 \\
\hline Yüksek & 30,6 & 32,6 & 39,6 & 51,6 & & \\
\hline
\end{tabular}

Tablo 15'te yer alan ifadenin sonucuna göre, p: 0,044<0,050 olduğu için $H_{0}$ hipotezi reddedilip, " $H_{1}$ : Yatırımcıların aşırı güvenleri ile finansal riskleri arasında farklllık vardır" hipotezi kabul edilmiştir.

Özet olarak; tüm değerlendirmeler göz önünde bulundurulduğunda "HA2: Yatırımcılarm aşırı güvenleri ile finansal riskleri arasında anlamlı bir ilişki vardır" hipotezi kabul edilmiştir.

\section{Aşırı güven ve spekülatif risk arasındaki ilişkinin Ki-Kare analizi}

Çalışmanın bu bölümünde, yatırımcıların aşırı güvenleri ile spekülatif riskleri arasındaki ilişki ki-kare testi ile analiz edilecektir. Bunun için spekülatif riski oluşturan ifadelerden sırasıyla ikinci, dokuzuncu ve onuncu maddeler analize tabi tutulmuştur.

“HАз: Yatırımcıların aşırı güvenleri ile spekülatif riskleri arasında anlamlı bir ilişki vardır." Buna göre kurulan hipotezler şu şekildedir:

Ho: Yatırımcıların aşırı güvenleri ile spekülatif riskleri arasında farklılık yoktur.

H1: Yatırımcıların aşırı güvenleri ile spekülatif riskleri arasında farklılık vardir.

Tablo 16. Aşırı Güven ve Spekülatif Risk Arasındaki İlişki - (Madde 2'ye Göre)

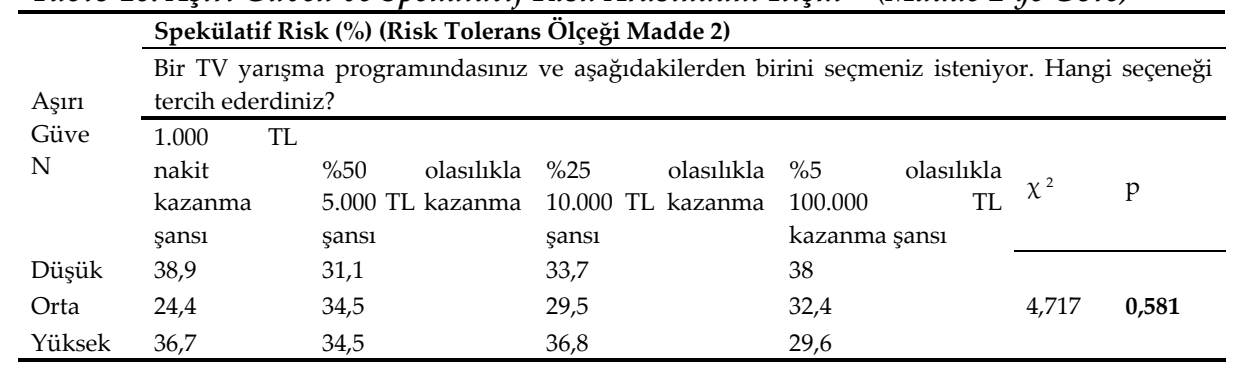


Tablo 16' da belirtilen ifadenin sonucuna göre, p: 0,581>0,050 değerine ulaşılmıştır. Buna göre" $H_{0}$ : Yatırımciların aşırı güvenleri ile spekülatif riskleri arasında farklılık yoktur" hipotezi kabul edilmiştir.

Tablo 17. Aşırı Güven ve Spekülatif Risk Arasındaki İlişki - (Madde 9'a Göre)

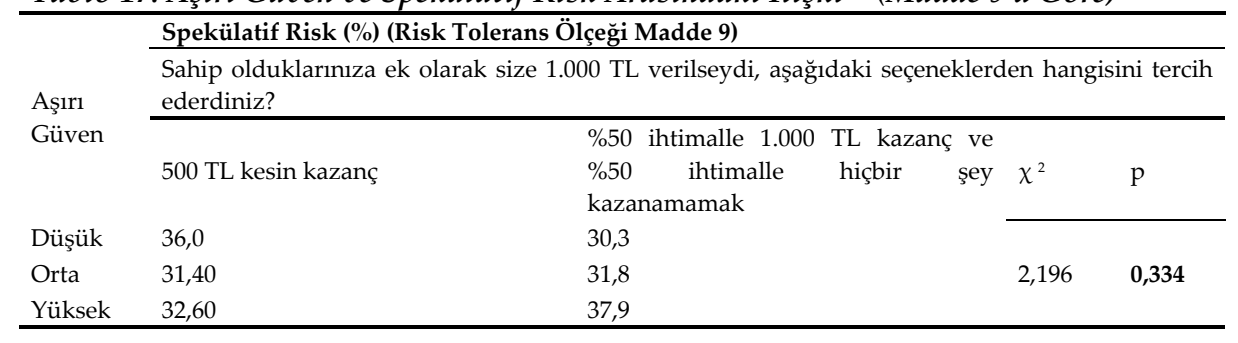

Tablo 17'de bulunan ifadenin sonucuna göre, p: 0,334>0,050 büyük olduğu için "Ho: Yatırımcıların aşırı güvenleri ile spekülatif riskleri arasında farklılık yoktur" hipotezi kabul edilmiştir.

\begin{tabular}{|c|c|c|c|c|c|c|}
\hline \multirow{3}{*}{$\begin{array}{l}\text { Aşırı } \\
\text { Güven }\end{array}$} & \multicolumn{6}{|c|}{ Spekülatif Risk Öğesi (\%) (Risk Tolerans Ölçeği Madde 10) } \\
\hline & $\begin{array}{l}\text { Sahip olduklarıniza ek olarak } \\
\text { ederdiniz? }\end{array}$ & 2.000 TL verilseydi, & aşağıdaki & seçenek & klerder & ni tercih \\
\hline & 500 TL kesin kayıp & $\begin{array}{l}\% 50 \text { ihtimalle } 1.000 \\
\% 50 \text { ihtimalle } \\
\text { kaybetmemek }\end{array}$ & $\begin{array}{l}\text { TL kayıp } \\
\text { hiçbir }\end{array}$ & $\begin{array}{r}\text { veya } \\
\text { şey }\end{array}$ & $x^{2}$ & $\mathrm{p}$ \\
\hline Düşük & 39,7 & 31,9 & & & & \\
\hline Orta & 29 & 32,4 & & & 2,682 & 0,262 \\
\hline Yüksek & 31,3 & 35,7 & & & & \\
\hline
\end{tabular}

Tablo 18'de belirtilen ifadenin sonucuna göre, p: 0,262>0,050 olduğu için "Ho: Yatırımcılarm aşırı güvenleri ile spekülatif riskleri arasında farklılık yoktur" hipotezi kabul edilmiştir. Diğer bir ifadeyle, bu maddeye göre yatırımcıların aşırı güvenleri ile spekülatif risk arasında bir ilişki mevcut değildir.

Özet olarak; tüm değerlendirmeler sonucunda" $H_{A 3}$ : Yatırımcıların aşırı güvenleri ile spekülatif riskleri arasında anlamlı bir ilişki vardır" hipotezi reddedilmiştir. 


\section{Tartırşma ve Sonuç}

Finansal açıdan risk toleransı, bireyin finansal kararlar verirken üstlenmeyi tercih ettiği risk miktarıdır. Genellikle sübjektif değerlendirmeler sonucunda elde edilen bulgulardan ulaşılabilecek risk tolerans seviyesi, finansal kararlarda kilit öneme sahiptir. Bunun nedeni; risk tolerans seviyesi belirlenmeden gerek bireyin gerekse finansal danışmanın birey için, uzun vadeli stratejik bir yatırım planı oluşturamayacağıdır.

Aşırı güven ise; bireylerin sahip oldukları yeteneklerin ortalamanın üzerinde olduğuna inanmasıdır. Ayrıca aşırı güvenli bireyler mevcut bilgilerinin çok önemli olduğunu düşünmekte ve bu bilgiler ile olayların sonuçlarını kontrol edebileceklerini varsayarlar.

$\mathrm{Bu}$ çalışmada aşırı güven ile risk toleransı arasındaki ilişki incelenmiştir. Yapılan analiz sonucu yatırımcıların aşırı güvenleri ile risk toleransları arasında anlamlı bir ilişki bulunmuştur. Elde edilen bulgularına göre, yatırımcların aşırı güven düzeyi yükseldikçe risk tolerans düzeyi de yükselmektedir. Bu bağlamda, yatırımcıların aşırı güven düzeylerini bilmeleri yatırım kararlarında üstlenebilecekleri risk toleransları üzerindeki etkisini fark etmeleri açısından önemlidir. Daha sağlıklı yatırım kararı alabilmek ve aşırı güven davranışını kontrol altında tutabilmek için eğitimler alınabileceği gibi yapılan finansal işlemler için işlem günlüğü tutmak faydalı olabilir. Bu bağlamda bireysel yatırımcılar günlük tutarak hangi kararı neden adlıklarını kayıt edebilecek, bu günlüğü zaman zaman gözden geçirdiklerinde kararlarının ardında yatan düşünce temellerini göreceklerdir.

Davranışsal finans alanında yapılan birçok çalışmada, bireysel yatırımcılar merkeze alınarak gerçekleştirilmiştir. Bu bağlamda, davranışsal finansın diğer unsurları da ayrıntılı olarak incelenerek, geniş bir kapsamda risk toleransı üzerindeki etkisi incelenebilir. Risk toleransı, sübjektif değerlendirmeler sonucu ortaya konulan bir olgudur. Dolayısıyla, detaylandırma yapmak alana ciddi katkılar sağlayacaktır.

Son olarak, aşırı güven ve risk toleransı finansal piyasalarda yatırım kararlarını önemli iki önemli olgudur. Bu bağlamda gelecekte yapılacak çalışmalarda bu olguların daha kapsamlı bir şekilde ele alınması bireysel yatırımcıların çok daha sağlıklı ve isabetli kararlar yol açacaktır. 
EXTENDED ABSTRACT

\title{
The Relationship between Risk Tolerance and Overconfidence in Investors
}

\author{
Yasemin Kuyucular - Durmuş Sezer \\ Adnan Menderes University
}

It is an undeniable fact that many factors affect investment decisions in financial markets and because of these factors decision-making becomes more difficult. In general, the reasons that make decision-making difficult may be divided into two; the reasons originating from the investor himself and the others. The personal characteristics and the behaviours of individual investors are the most important factors that affecting the investment decision.

In their decision models, investors have to use at least four factors as input. These are generally targets, time horizon, financial stability and risk tolerance. The first three can be evaluated by objective measurements but Risk Tolerance can be evaluated by subjective measurements. Risk tolerance level has a key importance in financial decision making. The reason is that without determining the risk tolerance level, both the individual investors and the financial advisors cannot create a long-term strategic investment plan.

The aim of this study is to determine the risk tolerance levels of individual investors and clearify the relations between the concept of overconfidence which effects investors'risk tolerance levels. In this context, risk tolerance and overconfidence behavior of individual investors in Turkey have been investigated in detail. In the scope of this study, a survey has been conducted to individual investors who are resident in İstanbul, Ankara and İzmir. Approximately 54\% of the investors live in these provinces. The reason why these cities selected is that due to its ability to better represent the research population.

Questionnaire technique was preferred as data collection method in the research. Questionnaires were directed to individual investors both face-to-face and electronically. The number of questionnaires included in this analysis was 520. Acceptable error level was found to be 0.05 and 
confidence level at 0.95 in the study. According to these calculations, acceptable sample size is 384 . In this context, 520 questionnaires is a sufficient sample size for the research.

For determining risk tolerance level, the scale is used in the study called "Financial Risk Tolerance Revisited: The Development of a Risk Assessment Instrument" by Grable and Lytton (1999a). This scale, which includes 13 multiple-choice questions, measures the risk tolerance of individual investors in the context of investment risk, financial risk and speculative risk components. The questions created to measure the overconfidence tendency of individual investors are prepared by examining the studies carried out by Langer and Roth (1975), Miller and Ross (1975), Svenson (1981), Odean (1998), Barber and Odean (2000), Nofsinger (2001) and Pompian (2006).

In this study, "Cronbach's Alpha" was used to test the reliability of the scales. As a result of the analysis, the Cronbach's Alpha value of the 13item risk tolerance scale was determined as 0.514 , and the same value of the 14-item overconfidence scale was determined as 0.857 . Data for this study were collected in April, May and June 2019.

In order to examine the relationship between investors' overconfidence and risk tolerance, three hypotheses were formed depending on a main hypothesis. The chi-square test was used for analysis. This analysis was preferred because the values used were categorical and the groups were independent from each other.

In determining the risk tolerance scores of individual investors, the values assigned for the options in each item by Grable and Lytton (1999b, p.3) were used. A "Risk Tolerance Score" is obtained by the sum of the scores of the answers given by each investor participating in the survey. Accordingly, the lowest risk tolerance score that can be achieved is 13 , and the highest risk tolerance score is 47 .

These scores were expressed in 5 different risk categories by Grable and Lytton (1999b, p.3). These categories were created according to the score ranges specified by the authors. In this study, the score ranges created by the aforementioned authors, the risk tolerance levels of investors positioned according to these ranges, and the derived codes specific to this study are included. 
According to this; "18 and below" score range is "Low Risk Tolerance" (RD1), "19 - 22" score range is "Below Average Risk Tolerance" (RD2), "23 - 28" score range is "Medium Risk Tolerance" (RD3), The score range of " $29-32$ " is considered as "Above Average Risk Tolerance" (RD4) and the score range of "33 and above" is considered as "High Risk Tolerance" (RD5).

In this study, following results have been obtained. The group with a "medium level" of risk tolerance $(41.9 \%)$ constitutes the largest group while "above-average risk tolerance" (31.5\%) group is the second, followed by the group with "below-average" risk tolerance $(9 \%)$. The smallest group constitutes the group with "low risk" tolerance level with $2.5 \%$; the group with a "high risk" tolerance level is expressed as $15 \%$.

A value was created based on the answers given by each of the investors to 14 overconfidence statements in the form of a 5-point Likert scale. A balanced distribution was observed in dividing the overconfidence of 520 people with a score range of 19 - 70 into 3 categories (low, medium and high). According to this, a histogram was created in "Excel" and 176 people has been found as low overconfident (between 19 and 42 points), 164 people as moderately overconfident (between 42.1 and 49.9 points) and 180 people as highly overconfident (between 50 and 70 points).

In order to examine the relationship between overconfidence and risk tolerance, overconfidence was subjected to a "chi-square" analysis as a triple and risk tolerance as a five-category. As a result of the analysis, a meaningful relationship was found between the overconfidence of the investors and their risk tolerance. According to the findings; as the overconfidence level rises, the risk tolerance level also increases.

After the relationship between the aforementioned concepts was found to be statistically significant, risk tolerance was divided into components (investment risk, financial risk and speculative risk) and the relationship between overconfidence was tried to be examined. In this context, unlike other studies, a clear distinction has been made in terms of concepts (components) expressing risk tolerance.

13-item scale Grable et al. (2011: 488), it measures three factors in investors. These are; investment risk (items: 4, 5, 8, 11 and 12), financial risk (clauses: 1, 3, 6, 7 and 13) and speculative risk (clauses: 2, 9 and 10). 
In this study, all three categories of overconfidence and each component of risk tolerance were subjected to chi-square analysis in terms of the items which they are expressed.

As a result of the analysis; a significant relationship was found between investors overconfidence and investment risks and financial risks. However, no significant relationship was found between speculative risk and overconfidence. This may be affected by the relatively unfavorable economic situation at the time data were collected. Therefore, different results can be obtained with studies to be carried out in different time periods.

\section{Kaynakça / References}

Ardehali, P. H., Paradi, J. C.and Asmild, M. (2005). Assessing financial risk tolerance of portfolio investors using data envelopment analysis. International Journal of Information Technology \& Decision Making, 4(3), 491-519.

Barber, B. M. and Odean, T. (2000). Trading is hazardous to your wealth: The common stock investment performance of individual investors. The Journal of Finance, 55(2), 773-806.

Barber, B.M. and Odean, T. (2002). Online investors: Do the slow die first? The Review of Financial Studies, 15(2), 455-487.

Bartlett, J. E.,Kotrlik, J. W. and Higgins, C. C. (2001). Organizational research: Determining appropriate sample size in survey research. Information Technology, Learning, and Performance Journal, 19(1), 43-50.

De Bondt, W. and Thaler R. H. (1995). Financial decision-making in marketsandfirms: A behavioral perspective in finance. Handbooks in Operations Research andManagement Science. Amsterdam: NorthHolland.

Dickason, Z. and Ferreira, S. (2018). Establishing a link between risk tolerance, investorpersonality and behavioural finance in South Africa. Cogent Economics EFinance, 6, 1-13.

Dittrich, D. A. V.,Güth, W. and Maciejovsky, B. (2005). Overconfidence in investment decisions: An experimental approach. The European Journal of Finance, 11(6), 471- 491.

Dumludağ, D., Gökdemir, Ö., Neyse, L. ve Ruben, E. (2015). İktisatta davranışsal yaklaşımlar. Ankara: İmge Kitabevi. 
Gigerenzer, G. (1991). How to make cognitive illusions disappear: Beyond "Heuristics and Biases". http://www.citeseerx.ist.psu.edu/viewdoc/download?doi (Erişim tarihi: 30.08.2018).

Grable, J. E. and Lytton, R. H. (1999a). Financial risk tolerance revisited: The development of a risk assessment instrument. Financial Services Review, 8, 163-181.

Grable, J. and Lytton, R. H. (1999b). Risk tolerance quiz with scoring grid. https://njaes.rutgers.edu/money/assessment-tools/investmentrisk-tolerancequiz.pdf(Erişim Tarihi:03.05.2019)

Grable, J. E., Archuleta, K. L. ve Nazarina, R. R. (2011). financial planning and counselingscales.,Grable, J. E., Archuleta, K. L. and Nazarina, R. R. (Editors), Measures of risk in (487-520). New York: Springer Science.

Kahneman, D. and Tversky, A. (1972). Subjective probability: A judgment of representativeness.Cognitive Psychology, 3, 430-454.

Klement, J. (2018). Risk Profiling and Tolerance: Insights for Private Wealth Manager.https://www.cfainstitute.org/-/media/documents/book/rfpublication/2018/risk compilation 2018.ashx (Erişim Tarihi: 03.04.2019).

Laibson, D. and Zeckhauser, R. (1998). Amos Tversky and the Ascent of BehavioralEconomics. Journal Risk and Uncertanity, 16, 7-47.

Langer, E. J. and Roth, J. (1975). Heads i win, tails it's chance: The illusion of control as a function of the sequence of outcomes in a purely chance task. Journal of Personality and Social Psychology, 32, 951-955.

McCannon, B. C.,Asaad, C. T. and Wilson, M. (2015). Financial competence, overconfidence, and trusting investments: Results from an experiment. Journalof Economics and Finance, 40, 590-606.

Menkhoff, L.,Schmidt, U. and Brozynski, T. (2005). The impact of experience on risk taking, overconfidence, and herding of fund managers: Complementary survey evidence.University of Hannover, Discussion Paper No. 292.

Miller, D.T. and Ross, M. (1975). Self-serving biases in the attribution of casuality: Fact or fiction? Psychological Bulletin, 82(2), 213-225.

MKK. (2017). Borsa trendleriraporu. https://www.tuyid.org/files/yayinlar/Borsa Trendleri Raporu XXII.pdf(Eri şim tarihi: 03.03.2018). 
Nofsinger, J.R. (2001). Investment madness. New Jersey: Prentice Hall.

Odean, T. (1998). Volume, volatility, price, and profit when all traders are above average. Journal of Finance, 53(6), 1887-1934.

Özdamar, K. (1999). Paket programlar ile istatistiksel veri analizi-1. (2. Baskı). Eskişehir: Kaan Kitabevi.

Peterson, R. L. (2018). Karar anı (2. Baskıdan Çev. Feyyat, C.). İstanbul: ScalaYayıncilı (Eserin orjinali 2007'de yayımlandı).

Pompian, M. (2006). Behavioral finance and wealth management: How to build optimal portfolios that account for mvestor biases. USA: John Wiley\&Sons, Inc.

Ricciardi, V. (2005). A research starting point for the new scholar: A uniqueperspective of behavioral finance. Social science research network. wwww.ssrn.com (Erişim tarihi: 27.06.2018).

Roszkowski, M. J. and Davey, G. (2010). Risk Perceptionand risk tolerance changes attributable to the 2008 economic crisis: A subtle but critical difference. Journal of Financial Service Professionals, July, 41-53.

Statman, M. (1999). Behavioral finance: Past battles and future engagements. Financial Analysts Journal, 55(6),18-27.

Svenson, O. (1981). Are we all less risky and more skillful than our fellow drivers? ActaPsychologica, 47, 143-148.

Tversky, A. and Kahneman, D. (1974). Judgment under uncertainty: Heuristics andbiases. Science, New Series,185(4157), 1124-1131.

\section{Kaynakça Bilgisi / Citation Information}

Kuyucular, Y. ve Sezer, D. (2021).Yatırımcılarda risk toleransı ve aşırı güven arasındaki ilişki.OPUS-Uluslararası Toplum Araştırmaları Dergisi, 18(42), 5398-5424. DOI: 10.26466/opus.928314. 